Anat. Inst. d. Mediz. Fak., Univ. Okayama (Vorstand: Prof. M. SEKI).

\title{
Supravitale Färbung der Bindegewebszellen mit Irisolechtviolett BBN, einem negativ geladenen, mittelstark polaren Farbstoff.
}

\author{
Irisolechtviolett BBN (負带電の中等極性染料) での結織細胞の超生染.
}

$$
\text { Toshiyuki HIRAI 平 井 敏之. }
$$

(Eingegangen am 15. August 1957.)

\begin{abstract}
Wenn es den wasserlöslichen basischen Farbstoffen gelingt, in das Innere der lebenden Zellen einzugehen, so färben sie präformierte Gebilde und Strukturen in diesen. Die Färbung erfolgt rasch, wie z. B. die supravitale Färbung mit wasserlöslichem Neutralrot oder Janusgrün schon in 20-40 Minuten ihren Höhepunkt erreicht. Dasselbe gilt von der supravitalen Färbung mit schwach basischen, mittelstark polaren, also schwer in Wasser löslichen Farbstoffen, wie TAMURA (1953) bei der Viktoriablaufärbung von Mitochondrien und Lipoidgranula in den subkutanen Bindegewebszellen der Maus und FUJISAWA (1955) bei der von Milchkügelchen in den Bindegewebszellen desselben Tieres beobachtet haben. Im Gegenteil färben die wasserlöslichen sauren Farbstoffe präformierte Gebilde in lebenden Zellen nicht, sondern sie werden allmählich in den Zellen in granulärer Form aufgespeichert. Daher wird die Färbung erst nach mehereren Stunden stark genug. Übrigens beschränken sich die so färbenden sauren Farbstoffe auf eine kleine Zahl, wie Trypanblau, Carmin u. dgl. Die speicherungsfähigen Zellarten werden auch nur in beschränkter Zahl gefunden, wie z. B. die Zellen der fibrohistiocytären und retikuloendothelialen Gemeinschaft und die Nieren- und Leberzellen. Bis jetzt scheint keine Angabe über das Gelingen einer schnellen und schönen supravitalen Färbung der präformierten Gebilde in den Zellen von höheren Tieren mit einem sauren Farbstoff in der Literatur vorzuliegen, ausgenommen seien allerdings die an dipolfreiem Neutralfett reichen Tropfen, die mit Sudan III u. dgl. färbbar sind. Ich suchte also unter den schwach sauren, mittelstark polaren Farbstoffen einen, welcher bezüglich der supravitalen schnellen Färbung dem schwach basischen, mittelstark polaren Viktoriablau gleichwertig ist, und konnte uuter den von SEKI (1956) in der Histologie eingeführten Farbstoffen Irisolechtviolett $B B N$ (von BAYER) ausfindig machen. Das Supravitalfärbung der Bindegwebszellen mit diesem Fasbstoff wird im Folgenden mitgeteilt.
\end{abstract}

\section{Material und Methode.}

Kurz vor dem Gebrauch wurde 0.1 cc 1\%iger alkoholischer Lösung von Irisolechtviolett BBN mit $10 \mathrm{cc}$ physiologischer Kochsalzlösung verdünnt. Man rasierte die Haare auf dem Lumbalteil der Maus, eröffnete die Haut, hob das Subkutangewebe mit einer Pinzette auf, schnitt von ihm Stückchen mit einer Schere aus und stellte sie in eine nicht zu geringe Menge von der oben erwähnten Farblösung hin- 
ein. Gleichlaufend wurden Gewebestückchen in einer etwa 5fachen Menge von physiologischer Kochsalzlösung 50 Minuten lang aufbewahrt und dann in die Farblösung übertragen. Man breitete die Gewebestückchen in der Farblösung etwas aus, damit der Farbstoff leichter in sie eindringe. Die Gewebestückchen blieben etwa 15 Minuten lang in der Farblösung bei $37^{\circ} \mathrm{C}$, wurden dann auf einem gereinigten $\mathrm{Ob}$ jektglas sorgfältig ausgebreitet und nach der Bedeckung mit einem Deckglas mikroskopiert und photographiert.

\section{Ergebnisse und Auswertung.}

a) Färbung des Bindegewebestückchens mit Irisolechtviolett BBN für etwa 15 Minuten gleich nach der Entnahme ans dem Tierkörper.

In Abb. 1 und 2 finden sich Fibrocyten, Fibrohistiocyten und Histiocyten. Der Kern der Fibrohistiocyten und Histiocyten ist, insofern die Zellen gesund bleiben, fast nicht gefärbt. Die Kernmembran wird jedoch deutlich schwach violett gefärbt, und an ihr sind relativ stark gefärbte Lipoidgranula gelagert. Dieser Befund stimmt mit dem von WOTTON und LEVIN (1957) an den Leberzellen des Kaninchens überein. Er fand im Kern der Leberzellen nach der Darreichung von mit Sudan IV gefärbtem Lebertran, Fettkügelchen, die sich oft mit einem Strang durch die Kernmembran mit einem ähnlichen Fettkügelchen im Cytoplasma verbanden. Im Cytoplasma dieser Zellen färben sich körnige, stabförmige und fadenförmige Gebilde, aber die Vakuolen bleiben ungefärbt. Die kleineren, speziell die länglichen unter ihnen sind meistens Mitochondrien, was sich aus den Befunden anderweitiger Untersuchungen bestätigt. Die größeren von ihnen sind angeschwollene Mitochondrien oder an Lipoid reiche Granula. Die Fibrocyten führen färbbare Granula weniger als die Fibrohistio- und Histiocyten.

Das Irisolechtviolett BBN ist bekanntlich mittelstark polar und löst sich in Lipoid am besten. Die mit ihm färbbare Kernmembran und die verschiedenartigen granulären Gebilde im Cytoplasma müssen also als lipoidreich angenommen werden.

b) Färbung des Bindegewebestückchens mit Irisolechtviolett BBN für etwa 15 Minuten nach 50minutigem Aufbewahren in physiologischer Kochsalzlösung.

Nach CHATANI (1929) sollen die nach dem Ausnehmen aus dem Körper in einer physiologischen Kochsalzlösung bei $37^{\circ} \mathrm{C}$ aufbewahrten Bindegewebszellen der Maus nach etwa 3 Stunden ihre Tuscheteilchen phagocytierende Fähigkeit einbüßen. Die Kernmembran von verschiedenen Zellen scheint, wie in Abb. 3 und 4 dargestellt ist, nach dem 50minutigen Einlegen der Zellen in physiologischer Kochsalzlösung mit Irisolechtviolett BBN deutlich stärker färbbar zu werden. Aber es ist nicht klar, inwieweit die Zunahme der Färbung auf einer Verstärkung der Färbung der Kernmembran selbst oder einer Vermehrung der Zahl und Färbungsstärke der an der Kernmembran gelagerten Lipoidgranula beruht. Im Cytoplasma der Zellen vermehren sich ferner die mit Irisolechtviolett BBN färbbare körnigen, stabförmige und fadenförmige Gebilde, und sie werden durchschnittlich stärker gefärbt als bei den obenerwähnten ganz frischen Zellen. Die Vakuolen im Cytoplasma färben sich nicht. 
Die in den grobgranulierten leukocytären Zellen mit gelochtem Kern enthaltenen Körnchen, die stark acidophil sind, werden auch mit Irisolechtviolett BBN ziemlich gut gefärbt.

Die Zunahme der Färbung mit Irisolechtviolett BBN der Kernmembran und verschiedenartiger Granulationen in den Zellen im Gewebestückchen, welches extra corpus in physiologischer Kochsalzlösung, welche aber in Wirklichkeit nicht ganz physiologisch ist, 50 Minuten lang aufbewahrt und also zum gewissen Grad beschädigt sind, ist offenbar zum Teil der Steigerung der Durchläßigkeit der Zellmembran und zum Teil der Lockerung der Eiweiß-Lipoidverbindung zuzuschreiben.

\section{Zusammenfassung.}

Es wurden an Stückchen des Bindegewebes aus dem Subkutangewebe der Maus die Kernmembran, Mitochondrien und verschiedenartige Granulationen der Bindegewebszellen mit einem schwach sauren, negativ geladenen Irisolechtviolett BBN (BAYER) supravital gefärbt. Dieser Farbstoff ist mittelstark polar und hat eine sehr spezifische Affinität zum Lipoid. Es gelang uns somit, die präformierten Gebilde in den Zellen mit einem sauren Farbstoff supravital distinkt zu färben.

\section{内 容 自 抄.}

二十日鼠の皮下から結合組織の小塊が取られ，生理的食塩溶液内に置かれ，そ して弱酸性染料で負に带電する Irisolechtviolett BBN (Bayer 製品)で結織細胞の 核膜，糸粒体，種々の形の粒子が染められた。 この染料は中等極性であって，特 に類脂質に強い親和性を持つ，かくて細胞の既存の物象を酸性染料で明瞭に超生 染することができたのである.

\section{Literatur.}

Chatani, R.: Über die Phagocytose der lebenden und toten Körpern entnommenen Bindegewebszellen. III. Die Phagocytose der Bindegewebszellen aus den Leichen von Menschen und Mäusen und der Einfluß der Wärme auf die Phagocytose. Juzen Igakukai Z. 34 (1926). - Fujisawa, K.: Untersuchung über die Veränderungen der Form- und Färbbarkeit bei in- und außerhalb der Zellen vorhandenen Milchkügelchen nach Einspritzung von Kuhmilch in die Unterhaut der Maus. Arch. hist. jap. 9 (1955). — Seki, M.: Methodik zur Färbung der freien dipolhaltigen Lipoide in ihren natürlichen Zuständen. Arch. hist. jap. 10 (1956). - Tamura, Y.: Supravitale Färbung der Bindegewebszellen mit Viktoriablau. Arch. hist. jap. 5 (1953). - Wotton, R. M. a. S. Levin: The direct absorption of previously stained lipid by nuclei in liver cells of the rabbit. Anat. Rec. 127 (1957). P. 390. 


\section{Erläuterung zu den Tafelabbildungen.}

Abb. 1 u. 2. Lebende Färbung der Bindegewebszellen der Maus mit Irisolechtviolett BBN gleich nach dem Entnahmen des Gewebestückchens aus dem Tierkörper. Die Kernmembran tritt gefärbt auf, mit ebenfalls gefärbten granulären Ablagerungen. Im Cytoplasma werden die Mitochondrien und verschiedenartige Einschlüße gefärbt, aber keine Vakuolen. $1000 \times$.

Abb. 3 u. 4. Lebende Färbung der Bindegewebszellen wie bei Abb. 1 und 2, aber erst nach 50minutigem Auf bewahren des Gewebestückchens in physiologischer Kochsalzlösung nach dem Entnommen desselben aus dem Tierkörper. Die Färbung verschiedenartiger Gebilde erfolgt deutlich stärker als bei Abb. 1 und 2. $1000 \times$. 
T. HIRAI
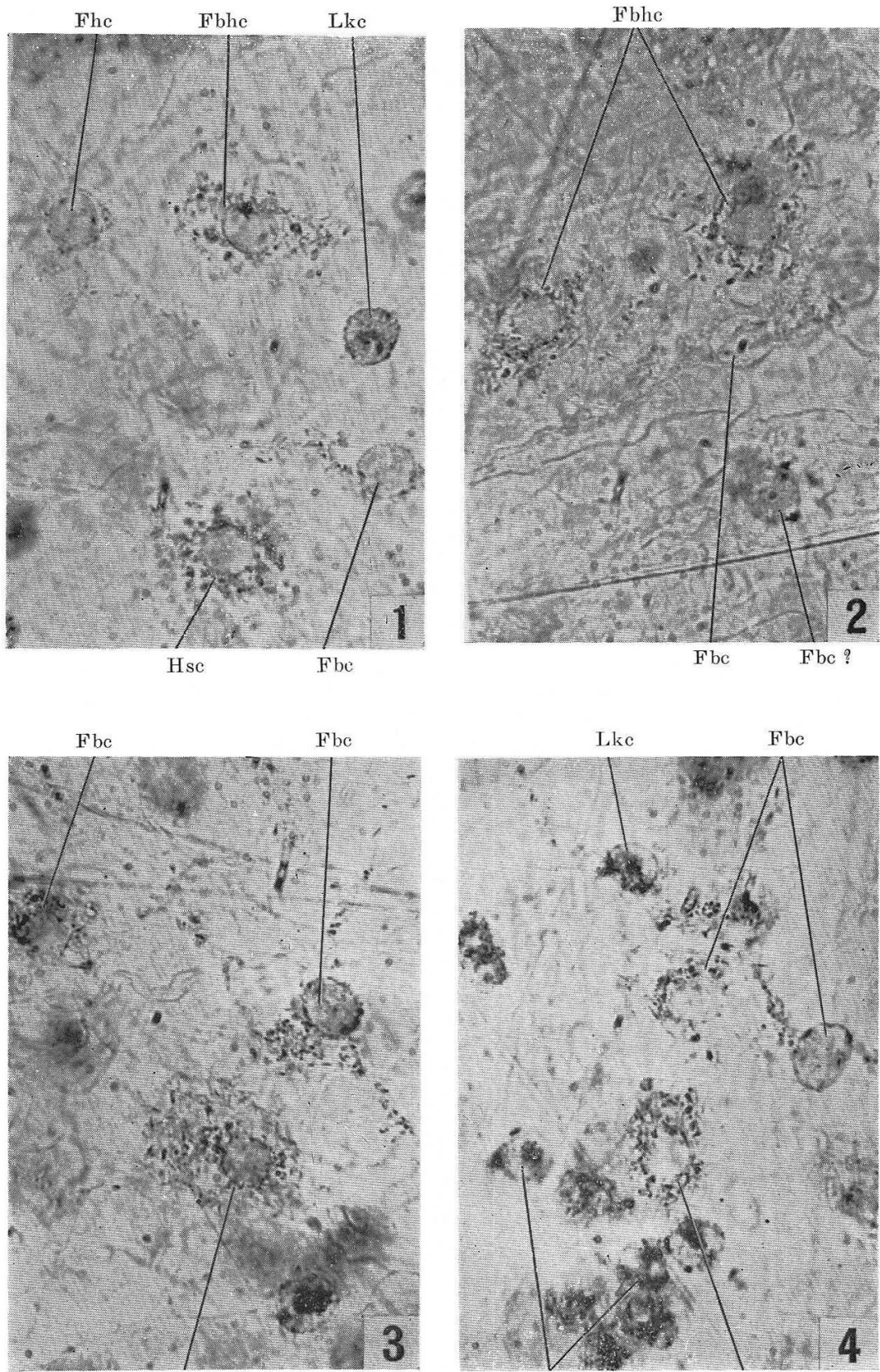

Fbhe

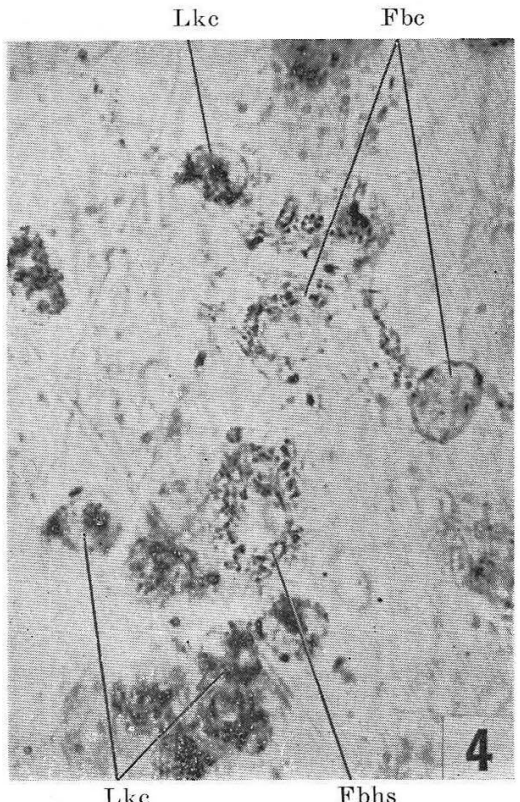

